\title{
O Desenvolvimento de Competências e o Serviço Público: Um estudo de Caso sobre Motivação com Funcionários da Prefeitura Municipal de Afrânio - PE
}

Daniele de Sousa Macedo ${ }^{1}$; Fernanda Roda de Souza Araújo Cassundé ${ }^{2}$

\begin{abstract}
Resumo: Este artigo apresenta uma analise dos fatores que influenciam a motivação no trabalho dos servidores públicos ativos na prefeitura municipal de Afrânio-PE, buscando-se apreender de que forma um modelo de gestão voltado para o desenvolvimento de competências poderá contribuir para a satisfação no ambiente de trabalho, nesse sentido, o objetivo do artigo é apresentar o quanto a aplicação do modelo de gestão por competências pode auxiliar na motivação dos servidores públicos. O desenvolvimento do presente trabalho foi realizado através de estudo de campo, sendo aplicado um questionário com os funcionários das secretarias de educação, saúde, agricultura, assistência social e funcionários ligados diretamente a prefeitura.O artigo apresenta um diagnóstico sobre como o modelo por gestão de competências pode ser adaptado ao setor público, ao mesmo tempo em que aponta as dificuldades associadas à aplicação desses conceitos na gestão de organizações públicas. Os resultados sugerem que os principais fatores desmotivadores apontados na pesquisa estão em consonância com o que discutem Klein e Mascarenhas (2014), assim, parece ser incontestável a importância da implantação do modelo de competências nas organizações públicas como ferramenta que auxilie a motivar os funcionários como também o estudo sobre esta área da administração, dada a ausência de pesquisas conforme apontado por Takahashi et al (2015).
\end{abstract}

Palavras-chaves: Motivação, Servidor Público, Desenvolvimento de competências

\section{The Competences Development and the Public Service: A Case Study on Employee Motivation of the Municipality of Afrânio - PE}

\begin{abstract}
This paper presents an analysis of the factors that influence motivation in the work of public assets servers in the municipal government of Afrânio-PE, seeking to grasp how a management model focused on skills development can contribute to meeting the environment work in this sense, the objective of this article is to present how the implementation of competency management model can help in motivating public servants. The development of this work was carried out through field study, a questionnaire applied to employees of the departments of education, health, agriculture, social assistance and linked directly to employees prefeitura.O paper presents an assessment of how the model for management skills can be adapted to the public sector at the same time points out the difficulties associated with the application of these concepts in the management of public organizations. The results suggest that the main demotivating factors identified in the survey are in line with discussing Klein and Mascarenhas (2014) thus it seems undeniable the importance of implementation of the competency model in public organizations as a tool that helps to motivate employees as also the study of this area of the administration, given the lack of research as reported by Takahashi et al (2015).
\end{abstract}

Keywords: Motivation, Public Servant, People management by competence

\footnotetext{
${ }^{1}$ Graduada em Administração ;

${ }^{2}$ Doutora, Mestre e Bacharel em Administração - UFPE. Professora Adjunta I do colegiado de Administração da Universidade Federal do Vale do São Francisco (UNIVASF) e Pesquisadora de projeto apoiado pelo CNPq cujo tema refere-se ao desenvolvimento de competências docentes para EAD. É revisora de periódicos e eventos acadêmicos da área. Avaliadora ad hoc da FACEPE (Fundação de Amparo à Ciência e Tecnologia do Estado de Pernambuco).
} 
Id on Line Revista Multidisciplinar e de Psicologia

Id on Line Revista Multidisciplinar e de Psicologia

\section{Introdução}

A administração pública, compreendida como o conjunto de ações e funções voltadas para o atendimento de necessidades da coletividade, necessita, assim como na administração privada de uma gestão de pessoas estruturada no intuito de promover a eficiência do serviço prestado. Quando se trata de gestão de pessoas também há de se considerar aspectos como a motivação no trabalho, pois os colaboradores precisam estar comprometidos com a organização, e a motivação é fundamental.

A utilização de ferramentas e técnicas que promovam melhorias na gestão de pessoas influencia no comportamento do servidor, assim, à medida que o mesmo percebe-se como um profissional valorizado pelo seu esforço dedicação e competência, há maiores probabilidades de que o mesmo sinta-se motivado no trabalho. Para Oliveira e colaboradores (2014) no ambiente interno, os membros da organização convivem entre si e, por este motivo há uma ligação com o grau de motivação e satisfação deles, quando o Clima Organizacional é favorável concede a possibilidade de satisfazer as necessidades desses membros [...].

O modelo de gestão de pessoas tradicional possui caráter autoritário, hierárquico, com ênfase na tarefa e na estrutura organizacional, não valorizando as competências dos indivíduos. Em contraposição, o modelo de gestão por competências visa desenvolver e valorizar talentos nas empresas. O profissional inserido dentro do modelo de gestão por competência deverá ser capaz de inovar-se desenvolvendo competências essenciais: habilidades técnicas, habilidades comportamentais, flexibilidade, capacidade de relacionamento e comunicação. Disponibilidade de aprendizagem constante bem como capacidade de aplicar esses conhecimentos.

O modelo de gestão por competências encontra barreiras para ser aplicado dentro do serviço público, pois o servidor público é visto como aquele que possui uma vida mansa e com pouca responsabilidade, e que, portanto não teria a incumbência de desenvolver as competências supracitadas. Em contraposição a esse equívoco, e no intuito de impulsionar a gestão de competências foi promulgado o decreto $\mathrm{N}^{\mathrm{o}}$ 5.707, de 23 de Fevereiro de 2006, instituindo a Política Nacional de Desenvolvimento de Pessoal, pelos órgãos e entidades da administração pública federal direta, autárquica e fundacional. Contudo na esfera municipal, freqüentemente não há preocupação com o desenvolvimento da carreira e a adequação das competências dos servidores junto aos órgãos da administração. Na medida em que o funcionário considera que seu potencial de realização profissional não é adequadamente aproveitado, que não é reconhecido pelo seu trabalho ou até mesmo que não recebe o devido treinamento para a execução de sua função, o trabalho deixa de ter um significado de realização, gerando conseguintemente desestímulo no trabalho. Nas palavras de Patrício e Casagrande: 
O significado do trabalho na qualidade de vida do ser humano está inserido na possibilidade não só de satisfações originadas a partir do uso de valor monetário oriundo do trabalho, mas também prazer pelo próprio trabalho. Precisamos pensar trabalho como ação humana que produz bens e serviços, não somente como meio de satisfazer necessidades de sobrevivência, mas também de transcendência: realização pessoal individual e coletiva, enquanto sujeito que transforma para si e para os outros seres humanos (1999, p.134).

O rompimento de modelos usuais na gestão de pessoas no serviço público torna-se necessário para adequação ás mudanças no mundo globalizado onde as pessoas devem ser cada vez mais dinâmicas, criativas e dispostas ao aprendizado, adquirindo e mostrando suas competências. Para Vieira (2011):

[...] a idéia de motivação no serviço público não está tão distante da realidade, mas os administradores públicos devem se conscientizar de sua missão e definir suas próprias metas pessoais e estimular seu crescimento profissional e melhorar a imagem da Administração Pública no país

Nesse sentido a gestão de pessoas por competências sob uma perspectiva de administração por carreira estimula o desenvolvimento pessoal envolvendo também o crescimento da organização. As pessoas são as responsáveis pela promoção de seus próprios projetos profissionais, mas cabe a organização oportunizar esse progresso. Nas palavras de Dutra (2004):

Um modelo de Gestão de Pessoas por Competências visa reconhecer, formar e ampliar conhecimentos, habilidades e atitudes, gerenciáveis na forma de grupos reunidos segundo suas similaridades funcionais, denominados de competências, de forma que agreguem valor à organização e ao indivíduo.

Sob essa perspectiva a implantação da gestão de pessoas por competências (GPPC) é significativa para a organização pública, visto que afalta de motivação no trabalho possibilita enormes problemas tanto para os funcionários quanto para a organização, em razão de possíveis percas na qualidade do serviço na produtividadegerando também stress, absenteísmo, falta de comprometimento entre outras consequencias.

Pensando em tudo isso, o presente trabalho se propôs a utilizar uma pesquisa visando demonstrar ao leitor a importância da implantação do modelo de gestão por competências como ferramenta significativa de transformação e melhoria na prestação de serviços públicos, através de estudo e resumo de artigos científicos que abordem o tema escolhido e da catalogação dos aspectos desestimuladores relatadospelos funcionários da Prefeitura Municipal de Afrânio-PE evidenciando a gestão por competênciascomo aspecto motivador. 
Id on Line Revista Multidisciplinar e de Psicologia

Id on Line Revista Multidisciplinar e de Psicologia

\section{Discussão Teórica}

\section{Satisfação com o trabalho}

A satisfação no trabalho é um tema muito discutido em pesquisas, embora não se tenha um consenso entre os teóricos, pois, como afirma Lima (et al 2015, p.3), "os estudos relacionados à satisfação no trabalho têm recebido contribuições [...] da teoria da hierarquia das necessidades, de Maslow, a teoria dos dois fatores, de Herzberg, a teoria da equidade, de Adams, e a teoria da expectativa, de Vroom”. A satisfação no trabalho é resultante do juízo que oindivíduo faz de seu trabalho é influenciada por situações e sensações que dão ao indivíduo a sensação de bem estar felicidade e alegria.

Um indivíduo pode se sentir satisfeito hoje com o seu trabalho e insatisfeitoamanhã com o que lhe é oferecido [...] Uma vez satisfeito com o trabalho, a tendência é que ele irá estender essa satisfação ao convívio social. Quando a felicidade engloba maior tempo do dia do indivíduo, seja em que ambiente estiver, possivelmente, ficará por mais tempo satisfeito durante o trabalho.(LIMA, 2015 p.05)

Tamayo(2000, apud CAPPI; ARAÚJO, 2015, p.07) afirma que pela abordagem unidimensional a satisfação está relacionada com o sentimento positivo que o servidor tem em relação ao seu trabalho, enquanto que na abordagem multifatorial, considera a satisfação sob diversas perspectivas. A satisfação não é sinônima de motivação. A satisfação é um indicador da motivação.Um servidor poderá sentir-se realizado com determinadas condições de trabalho (remuneração, por exemplo), sem, no entanto motivar-se em relação à função que executa.

A satisfação com o trabalho é uma atitude geral de uma pessoa em relação ao contexto ocupacional de que participa, sendo que a avaliação que um trabalhador faz de sua satisfação ou insatisfação é resultante de um somatório de diferentes elementos.(ANDRADE et al ,2007 p.09).

As consequiências mais comuns da insatisfação no trabalho são o absenteísmo, a rotatividade,desperdício de materiais, ociosidade, conflitos, baixo comprometimento com a organização.

A satisfação dos colaboradores no ambiente de trabalho está sendo considerada fundamental nas organizações bem-sucedidas. De acordo com essa constatação, desenvolver pesquisas que possibilitem identificar o grau de satisfação dos clientes internos de uma organização é um aspecto de extrema relevância. Isso porque tornase possível estabelecer os fatores determinantes dessa satisfação, além de identificar oportunidades de melhoria das condições de trabalho implicadas na redução dos índices de turnovere, consequentemente, numa maior produtividade e lucratividade das organizações.(NODARI e CAMARGO,2010 p. 02) 
Id on Line Revista Multidisciplinar e de Psicologia

Id on Line Revista Multidisciplinar e de Psicologia

Muitos líderes acreditam que o profissional satisfeito terá um melhor desempenho, de fato há uma relação entre desempenho e satisfação, mas pondera Paula et al (2011, p.03), o bom desempenho causa satisfação quando há reconhecimento e recompensas.

\section{Motivação}

A Motivação, apesar de ser um estudo específico da área de Psicologia, é também pesquisada pela teoria administrativa, no intuito de criar condições proveitosas ás organizações. "Motivação é o resultado da interação entre o indivíduo e a situação que o envolve" (MASLOW, 1996). A motivação varia entre as pessoas, e até mesmo entre períodos diferentes numa mesma pessoa. A necessidade é uma carência interna do indivíduo, quando essa carência não é suprimida, provoca o rompimento do estado de equilíbrio do organismo criando tensão e estimulando impulsos no individuo para reduzi-la ou atenuá-la.

Quanto à motivação no serviço público Hinna; Russo; Scarozza( 2012 apud HASHI ,2015p. 05), argumenta que essa preocupação tem se mostrado crescente nos últimos anospela necessidade de melhoria de desempenho no serviço público.

"O setor público é tratado como um chamado, senso de dever, em vez de ser considerado um emprego" (PERRY, 1996; HOUSTON, 2000, 2005 apud TAKAHASHI et al 2015, p.05). servidores públicos, na grande maioria não contam com gratificações pelo desempenho apresentado, sendo desprivilegiados em relação ao emprego privado.

[...]No serviço público há um círculo vicioso em que os servidores se sentem desvalorizados e esquecidos pelos governantes e desprestigiados pelos usuários dos seus serviços, enquanto que o governo não conta com a garantia da fidelidade de servidores que não escolheu e, por fim, aos cidadãos contribuintes resta submeter-se ao resultado disto tudo que, às vezes, chega ao descaso.(CARVALHO,2008)

"O empregado trabalha com mais compromisso, lealdade e entusiasmo na medida em que as expectativas são compartilhadas [...]" (SCHEIN1993 apud BATISTA; SANTOS, 2015,p. 05). "A motivação não é nem uma qualidade individual,nem uma característica do trabalho: não existem indivíduos que estejam sempre motivados, nem cargos igualmente motivadores para todos" (LÉVYLEBOYER 1994, p. 138 apud BATISTA; SANTOS, 2015,p.05). Destarte, o funcionário faz uma

avaliação do ambiente organizacional analisando o próprio nível de satisfação/insatisfação no trabalho. Para Carvalho(2008), os principais fatores internos e externos que desmotivam os servidores públicos, sobretudo os das áreas que não contam com plano de carreira bem definido são: 
$\checkmark \quad$ As culturas egocêntricas daqueles que sempre julgam que o salário está abaixo do ideal e, por isso, atendem mal o público;

$\checkmark \quad$ A estabilidade, que é conferida exatamente para garantir uma prestação de serviço igualitária e com qualidade, mas acaba fazendo com que o servidor se acomode e pior, atenda o cidadão como se estivesse lhe fazendo um favor;

$\checkmark \quad$ A constatação de que muitas decisões políticas superam as decisões técnicas e os fartos exemplos de corrupção também desmotivam os servidores;

$\checkmark \quad$ A inevitável convivência com servidores mais antigos desmotivados que passam metade de suas vidas reclamando do serviço, mas que por comodismo ou incompetência não o deixam;

$\checkmark \quad$ A famigerada ideia popular de que o servidor público não gosta muito de trabalhar também acaba sendo um fator que o desmotiva cada vez mais;

$\checkmark \quad$ A falta de pessoal e de meios para atender a demanda que cresce a cada dia;

$\checkmark \quad$ A nítida falta de comprometimento com o trabalho público por parte de vários chefes que não estabelecem objetivos e metas para os administrados e exigem resultados de acordo com os interesses do momento;

$\checkmark \quad$ A percepção inequívoca de que, às vezes, o serviço público é usado com fim eleitoreiro também tira a satisfação de qualquer atividade.

$\checkmark$ Assim, o cultivo da motivação no serviço público exige programas permanentes que conscientizem cada servidor de que:

$\checkmark \quad$ Ser remunerado para facilitar a vida do próximo é um privilégio e, em última análise, esta é a razão de sua atividade;

$\checkmark \quad$ Para cada usuário do serviço público o seu problema é o mais grave;

$\checkmark \quad$ Cada um deles representa o serviço público como um todo;

$\checkmark \quad$ A imagem do funcionalismo público pode e deve ser melhorada, a partir da excelência no atendimento a cada cidadão e do entusiasmo de cada servidor;

$\checkmark \quad$ Em seu próprio benefício, deve manter o entusiasmo do início da carreira, não se deixando contaminar pelos pessimistas de plantão atendidas.

Muitas das dificuldades sentidas derivam das singularidades organizacionais do setor público, quando em comparação com o setor privado e mesmo com o setor não lucrativo(LIRA e SILVA, 2015).Há um senso comum de que os motivos dos funcionários públicos são diferentes dos motivos dos funcionários do setor privado Perry; Hondeghem (2010 apud TAKAHASHI et al, 2015 p. 09).

"Além de motivações, os funcionários públicos têm expectativas diferentes em comparação aos empregados de empresas privadas" (CREWSON 1997 apud RODRIGUES et al, 2014 p.04). "O motivo para servir o bem público é prevalecente na força de trabalho das instituições públicas e essa diferença deve ser aproveitada como força motivadora pelos gestores “(MANN 2006 apud RODRIGUES et al, 2014 p. 05).O servidor público busca também a estabilidade, incentivo monetário, e se interessa pela nobreza da missão do serviço público. Takahashi et al (2015 p.10) argumenta que os funcionários públicos são mais propensos a colocar um valor maior na recompensa intrínseca do trabalho, ao sentimento de realização [...].

A motivação dos funcionários públicos é uma variável crucial para o funcionamento das organizações públicas e afeta a sua capacidade de prestar serviços públicos de forma eficiente, eficaz e equitativa, considerando que os sintomas de baixa motivação incluem apatia, absentismo, atrasos, desempenho inconsistente e o evitar da responsabilidade pessoal.(DOHERTY eHORNE, 2002 apud LIRA; SILVA, 2015 p.03) 
Para Wise, 1990; Perry, 1996 (apud TAKAHASHI et al, 2015, p.06)“A motivação no serviço público é formada como uma combinação de atração ao funcionalismo, compromisso com valores públicos, compaixão e autossacrifício".No tocante as teorias motivacionais Lashey E Lee-Ross (2003 apud RODRIGUES 2014,p.04) classificam as teorias da motivação em dois grupos [...] o primeiro grupo foca a satisfação das necessidades dos indivíduos. O segundo foca o processo cognitivo envolvido a partir da criação de prioridades em função das necessidades motivacionais de cada um: são as teorias cognitivas.

[...] o grupo das teorias das necessidades (...) destaca as necessidades internas das pessoas e o comportamentoresultante do esforço por elas realizado para reduzir ou saciar essas necessidades. [...]parte desse grupo: a Teoria das Necessidadesde Maslow; a Teoria das Necessidades de Frederick Herzberg; a teoria das necessidades deAlderfer (ERG) e a teoria das necessidades de McClelland. Com relação às teorias cognitivas[...]focalizam-se na compreensão do processo subjacente à motivaçãopara o trabalho, tentando explicá-la através do enfoque numa insuficiência ao nível dasnecessidades e no comportamento resultante dessa situação". As teorias que se enquadramnesse grupo são: a teoria da equidade, a teoria do reforço, a teoria da definição de metas ea teoria das expectativas. (FREITAS 2006 apud RODRIGUES et al, 2014,p.04)

Diante dos pressupostos apresentados pelos autores é possível perceber diferenças entre os fatores que motivam as pessoas a prestarem serviço público das que preferem assumir outras atividades distintas, ao mesmo tempo em que se verifica que apesar desse contraste o servidor público também precisa estar motiva dona execução de suas funções.

\section{Gestão de Pessoas por Competências e aEstratégia de Implantação para o Setor Público.}

Um modelo de gestão de pessoas é o meio pelo qual uma organização administra e orienta o comportamento humano no trabalho, delimitando estratégias e processos de gestão. Nesse sentido a gestão de pessoas por competências deve atuar sob a óptica de administração de carreiras.Dultra (2004) afirma que "A carreira não deve ser entendida como um caminho rígido a ser seguido, mas como uma seqüência de posições e de trabalhos realizados pelas pessoas. A essa sequência ele intitula como "carreira".

Cabe a empresa estimular as pessoas no seu desenvolvimento profissional. É sobre essa perspectiva que muitas organizações empregam a gestão por competências detectando as competências que o funcionário deverá possuir para exercer uma determinada função.SegundoLeme (2005) a gestão por competências é o processo de conduzir os colaboradores para atingirem as metas e os objetivos da organização através de suas competências técnicas e comportamentais. 
A importância da aprendizagem individual é óbvia e sutil, primeiro porque as organizações são compostas de indivíduos e sutil porque as organizações podem aprender independente de um indivíduo, mas não de todos. [...] pode-se dividir a aprendizagem individual em dois níveis: operacional e individual, ou seja, implica um know-how (produzir uma ação) e knowwhy(compreender conceitualmente uma experiência). (KIM 1998 apud COMINI et al, 2008,p.06)

As principais dificuldades na implantação da GPPC( Gestão de pessoas por competência)em organizações públicas estão ligadas a legislação e ao fundamento organizacional altamente hierarquizado, além da centralização, corporativismo, fortepaternalismo nas relações funcionais, descontinuidade administrativa... Faltam iniciativas dos gestores públicos nesse sentido, pois a inserção daGPPCexige mudanças organizacionais profundas.Através de um estudo de campo Munck et al (2011) afirmou que:

É possível compreender que as dificuldades em lidar com o modelo de gestão por competências passam por incompreensão, pelo não cumprimento de suas regras, pelo descomprometimento de gestores e pela não utilização e desenvolvimento das ferramentas de apoio, o que desarticula seus fundamentos.( MUNK, 2011, p 31).

“A legislação que regula as relações de trabalho no setor público é inadequada, principalmente por seu caráter protecionista e inibidor do espírito empreendedor" (OSBORDE e GAEBLER, 1994 apud VIEIRA 2011,p.08)

Scelsa e Costa, ainda levantam a problemática relacionada ao sistema derealização de concursos públicos, como se observa:

Verifica-se ainda, que os concursos públicos, muitas vezes, são realizados sem nenhuma regularidade e avaliação periódica da necessidade de quadros, fato que leva à admissão de um contingente excessivo de candidatos de uma só vez, seguida de longos períodos sem uma nova seleção, o que inviabiliza a criação de verdadeiras carreiras e a renovação necessária dos quadros funcionais(SCELSA E COSTA, 1991 apud VIEIRA 2011, p 08)

À vista disso, o setor público deve realizar um mapeamento de competências, utilizando um recrutamento eficiente e rigoroso para que as pessoas contratadas possuam o perfil desejado,possibilitar uma estrutura de carreira através da progressão funcional;investir nos adicionais de titularidade e de gestão pública respeitando limites financeiros e orçamentários previstos na Lei de Responsabilidade Fiscal; realizar efetivamente o sistema de avaliação de desempenho; investir no treinamento do servidor e alocá-lo de acordo com sua formação acadêmica, experiência e perícia. $\mathrm{O}$ servidor deverá sentir-se motivado a desempenhar sua função com eficiência, disposto a contribuir com o serviço público ao invés de torna-se omisso ou inerte após assumir um concurso público.

Quanto às recomendações é necessária uma nova perspectiva, é preciso transformar a estabilidade do servidor público, de uma fraqueza da GPPC numa força. Usar a estabilidade como uma forma não de estagnação, mas como segurança para 
experimentar a evolução e habilitar a melhoria. Como não há o risco da demissão, o profissional pode ousar evoluir sem medo (AMARAL, 2008, p.15)

\section{A relação entre o desenvolvimento de competências e a motivação no serviço público}

A motivação decorre da própria percepção dos indivíduos em relação a si e ao trabalho, a natureza da relação afeta a sua motivação, assim o servidor que sentir-se capacitado para desenvolver sua função, e que perceber-se como agente valorizado pelos serviços prestados, com possibilidade de desenvolvimento de carreira terá alta probabilidade de ser motivado na execução desuasfunções. Ocorre que o funcionário público na maioria das vezes é visto como mero recursoe não como pessoa que fortalece a organização. É necessária a substituição de uma administração pública estigmatizada, com servidores pouco experientes e apáticos em suas funções, por uma melhor gestão de recursos humanos. Nesse sentido, "O modelo de gestão por competências busca, entre outros objetivos, identificar e selecionar profissionais competentes, alinhados com as diretrizes e os objetivos estratégicos organizacionais" (ENAP, 2005).

Verifica-se que apesar do modelo adotado atualmente pela administração pública ser o gerencial, ainda há resquícios da administração patrimonialista onde até mesmo a distribuição de cargos comissionados beneficia o próprio gestor.

A administração patrimonialista vem a ser como uma administração egoísta em sua estrutura, pensando apenas no administrador, beneficiando a quem lhe convém, ou seja, usa o poder para beneficiar-se, tanto de maneira financeira quanto de outros modos, como contratação de pessoas ou concessão de cargos aos que em alguma ocasião passada, presente ou futura poderá de algum modo ser útil a ele (BERGUE 2010)

Essa cultura patrimonialista é um fator desmotivador presente em muitos órgãos públicos. O funcionário público inserido nessa cultura estará condenado à apatia por perceber que não será valorizado pela sua competência nem tão pouco haverá possibilidades de crescimento dentro da organização.

As competências individuais devem ser um dos principais requisitos para o preenchimento das vagas públicas. Destarte, a constituição de um quadro de pessoal adequado deve ir além do domínio de conhecimentos técnicos e ancorar-se na contratação de servidores que possuam um conjunto de habilidades e atitudes compatíveis com suas futuras atribuições (ENAP, 2005).

Nesse seguimento,com a valorização profissional, e o reconhecimento dos serviços prestados pelo servidor (resultando melhor remuneração), promove-se a motivação no trabalho combatendo a letargia dos funcionários e elevando os níveis de eficiencia e eficácia da organização. 
[...] umdosaspectos da qualidade de vidaquemerece mais atençãoé a Qualidade de Vida no Trabalho. É nachamadaatividadelaboralque o ser humano passa umterço de seu dia e osmelhores e mais produtivosanos de sua vida. Quando o tempo passado no trabalhoé vivido de forma digna, o homem se sente feliz e transmite esse sentimento para osquelhecercam, formando umaverdadeira rede de felicidade. (OLIVEIRA 1998 apud OLIVEIRA E MEDEIROS 2011)

\title{
Metodologia
}

O presente trabalho é classificado como um estudo de natureza descritiva que apresenta a síntese de estudos teóricos e disponibilizados no meio acadêmico, bem como a utilização de uma abordagem quantitativa através da aplicação de um questionário como instrumento de pesquisa com os servidores da prefeitura municipal de Afrânio-PE.Quantos aos meios de investigação trata-se de uma pesquisa bibliográfica e de uma pesquisa de campo. Caracteriza-se ainda como um estudo de caso, já que apresenta "descrição detalhada do cenário e das pessoas, seguida por análise de dados para temas ou questões" (CRESWELL, 2007, p. 195).

Assim, foi realizado inicialmente um levantamento bibliográfico fazendo uma análise sobre os principais fatores motivadores do trabalho, principalmente no serviço público, e posteriorrmente buscou-se relacionar esses fatores com os aspectos norteadores da gestão por competencia, verificando como a GPPC é fundamental para estimular a motivação no serviço público.

\begin{abstract}
A pesquisa bibliográfica é, como se vê, uma fase da revisão de literatura, assim como é fase inicial para diversos tipos de pesquisa. O ciclo começa com a determinação e delimitação do tema e segue com o levantamento e a pesquisa bibliográfica. A partir desta é que se organiza a revisão que, conforme descrito anteriormente requer postura crítica, cotejo das diversas opiniões expressadas.(MOREIRA 2014, p.06)
\end{abstract}

Posteriormente foi realizado um estudo de campo, através da aplicação de um questionário com os servidores da Pefeitura Municipal de Afrânio. Optou-se por trabalhar com esse instrumento de coleta de dados por ele possibilitar uma análise objetiva das informações, sem interferência do pesquisador. Os dados obtidos através dos questionários foram subsequentemente analisados com auxílio de software específico para análise de dados nas ciências sociais.Os passos de coleta de dados incluem estabelecer as fronteiras para o estudo, coletar informações [...] bem como estabelecer o protocolo para registrar informações [...] do local e das pessoas propositadamente selecionadas" segundo Creswell (2007, p.189).

O universo da pesquisa compreendeu 50(cinqüenta) servidores da referida organização pública, incluindo 35 servidores contratados. Os funcionários foram selecionados aleatoriamente, 
Id on Line Revista Multidisciplinar e de Psicologia

Id on Line Revista Multidisciplinar e de Psicologia

desde que estivessem na "ativa", ou seja, não foram pesquisados funcionários em licença, de férias ou aposentadosem quantidades iguais de cada secretaria da prefeitura para responderem o questionário.

\section{Resultados e Discussões}

Foram entrevistados 50(cinqüenta) servidores da prefeitura municipal de Afrânio-PE. O último concurso realizado pela prefeitura foi no ano de 2010 para preenchimento de vagas em inúmeros cargos secretaria de saúde, secretaria de agricultura, secretaria de assistência social e funcionários ligados diretamente a prefeitura.

No item Autonomia, as respostas foram bem diferentes, dependendo do setor onde os funcionários trabalhavam. $\quad 38$ funcionários responderam que sempre tem liberdade para fazerem o seu trabalho da forma como consideram melhor. 40 entrevistados consideram que raramente a empresa exige um procedimento rígido para a execução de suas atividades.

Sobre a realização profissional, $76 \%$ consideram regular sua satisfação com o cargo. Existe um índice elevado de insatisfação (20\%), indicando haver necessidade de maior atenção para com esses funcionários por parte da gestão de pessoas, já que, aproximadamente, $70 \%$ dos entrevistados raramente ou quase nunca possuem um sentimento de realização profissional. Quanto à quantidade e qualidade de trabalho, $64 \%$ das pessoas afirmaram que não estão plenamentes satisfeitas em relação ao trabalho. Em relação a melhoria na realização do trabalho, $60 \%$ dos entrevistados atribuíram nota inferior a 7. Quanto a comunicação, $100 \%$ dos funcionários responderam que a empresa se comunica adequadamente com seus funcionários. Apenas $54 \%$ dos funcionários pesquisados, sentem-se seguros em dizer o que pensam, os demais afirmaram que raramente sentem-se seguros ou não tem opinião. Esses dados podem justificar os elevados índices de rotatividade de pessoal e a famosa ineficiência das instituições públicas de nosso país, conforme aponta Rutkowski (1998).

“A motivação intrínseca encontra-se associada à realização pessoal ou ao trabalho em si, ou seja, a motivação intrínseca refere-se a uma necessidade psicológica inata para a competência e autodeterminação" (LIRA; SILVA, 2015 p.05). Nesse sentido, os dados apontam que 78 \% dos servidores não sentem que seu potencial é devidamente aproveitado, ou seja, há uma percepção de não realização pessoal que afeta a motivação dos mesmos.

No quesito relacionamento interpessoal, os entrevistados afirmaram que sim, existe um relacionamento de cooperação entre os departamentos da empresa, $70 \%$ dos funcionários afirmaram que o relacionamento entre os funcionários é adequado, enquanto que os demais afirmaram que o relacionamento era razoável.

Sobre valorização profissional, $74 \%$ dos servidores assinalaram que raramente a empresa reconhece os bons funcionários, $6 \%$ disseram não ter opinião, $10 \%$ disseram nunca, $6 \%$ disseram 
quase sempre, $4 \%$ disseram sempre. No que diz respeito ao treinamento /desenvolvimento, quando questionados se receberam o devido treinamento para a execução de seu cargo,56\% pessoas marcaram que não, $30 \%$ pessoas marcaram mais ou menos e $14 \%$ marcaram que sim. Quando questionados se a empresa investia em treinamento para, o desenvolvimentoprofissional dos seus funcionários, $78 \%$ das pessoas marcaram que não, $16 \%$ marcaram mais ou menos e $6 \%$ marcaram que $\operatorname{sim} .78 \%$ dos entrevistados marcaram que raramente a empresa investe em treinamento /desenvolvimento para que tenham um aprendizado contínuo.

A ausência do modelo por gestão por competências, ocasiona a ausência de treinamentos, fator este que é imprescindível para eliminar atos inseguros, pelos dados coletados fica claro que a implantação do GPPC melhoraria o desempenho da organização.

É a organização que cabe a responsabilidade de tomar a iniciativa do projeto como um todo. Ela deverá assessorar as pessoas e deixar suas posições bem claras perante seus empregados para que estes possam se posicionar. Ela também terá que criar condições para que o projeto saia do papel. Por exemplo, precisará alterar seu processo seletivo, seu sistema de remuneração, de avaliação de desempenho, de treinamento e desenvolvimento, terá que preparar a média gerência para repartir boa parte do seu poder com os empregados do chão de fábrica, entre outras coisas. Ou seja, iniciar, acompanhar, assessorar, medir resultados, dar feedbacks necessários, ter um planejamento estratégico condizente com o projeto, sinalizar as competências individuais e organizacionais que serão valorizadas, são atividades de responsabilidade da organização (SILVA, 2003 apud AMARAL, 2008, p. 08 ).

Quanto a estabilidade no emprego ,70\% dos entrevistados que são funcionários contratados marcaram que não se sentiam seguros em relação a estabilidade no emprego.Os demais $30 \%$ são efetivos e marcaram que sim, se sentiam seguros em relação a estabilidade no emprego.

No quesito imagem da empresa, 98\% dos funcionários responderam que consideram a empresa um bom lugar para trabalhar e que indicariam um amigo para trabalhar nela. $70 \%$ dos servidores assinalaram que consideram a empresa sempre ética com seus funcionários/clientes/parceiros. $20 \%$ assinalaram raramente e $10 \%$ assinalaram quase sempre.

Nesse sentido, questiona-se: se os funcionários não tem uma realização plena no trabalho nem, tampouco, consideram-se seguros, quais razões os levam a considerar a empresa um bom lugar para trabalhar? Seria, nesse caso, o benefício da estabilidade, concedidos pela Constituição Federal, que justificariam a indicação da empresa? Oliveira e Krom (2004) chamam a atenção para o fato de que a estabilidade no serviço público também está relacionada a baixa qualidade do serviço prestado. Assim, ao serem solicitados a indicar as duas principais razões pelas quais trabalhavam na empresa, a falta de opção de outro emprego (46\%) e a estabilidade (30\%) foram os dois motivos mais citados. Essa motivação de ingresso no serviço público, quando voltada à realidade brasileira, visa à busca de estabilidade no emprego e tende a ser baseada no foco em melhores salários (TAKAHASHI et al, 
Id on Line Revista Multidisciplinar e de Psicologia

Id on Line Revista Multidisciplinar e de Psicologia

2015,p.09), a pesquisa demonstra a veracidade desse fato, grande parte das pessoas procuram o serviço público em busca da estabilidade.

Os principais fatores desmotivadores foram apontados na pesquisa e em consonância com o que discutem Klein e Mascarenhas (2014). Nesse sentido, 92\% dos entrevistados indicaram que fatores motivacionais intrínsecos, tais como a relevância e natureza do trabalho, seriam mais importantes para a motivação dos servidores do que fatores motivacionais extrínsecos, como remunerações, salários e benefícios.

\section{Conclusões}

Este trabalho buscou identificar, na PMA - Prefeitura Municipal de Afrânio-PE os fatores necessários para a motivação no serviço público, relacionando essas condições com a GPPC (gestão por competência) e identificando as principais contribuições que a mesma pode oferecer para promover a satisfação no trabalho.

Os resultados foram obtidos majoritariamente através da aplicação de questionários a servidores ativos na supracitada prefeitura, demonstrando que a falta de oportunidade de crescimento na carreira, a desvalorização profissional em relação aos salários e o não aproveitamento de seu potencial são os principais aspectos desmotivadores que poderiam ser melhorados ou eliminados com aaplicação da GPPC.

O estudo revelou um alto nível de insatisfação e desmotivação no trabalho devido à falta de reconhecimento dos profissionais, isto ligado ao pouco investimento em treinamentos para o bom desempenho dos servidores. É notável que eles sentem-se úteis para a organização e que de fato avaliam a prefeitura como um lugar bom para trabalhar, desde que haja o reconhecimento dos profissionais através do estabelecimento de planos de carreira, sendo viável através da implantação da gestão de pessoas por competências.

A motivação no serviço público, para Takahashi (2015), é um tema pouco explorado no Brasil, visto que entre os anos de 1997 e 2006, foram encontrados apenas 11 artigos publicados nos Encontros Nacionais da Associação Nacional de Pós-Graduação e Pesquisa em AdministraçãoEnanpad.

Assim, é incontestável a importância da implantação do GPPC nas organizações públicas como ferramenta que auxilie a motivá-los bem como o estudo sobre esta área da administração. O servidor consciente de seu papel através da gestão por competências dentro da organização se sente motivado a contribuir procurando trazer resultados ao serviço público. A gestão por competências une os objetivos da organização aos interesses individuais dos funcionários. Diante de grandes mudanças no mercado de trabalho, o setor público também é passível de melhorias. Sabe-se que muitos 
Id on Line Revista Multidisciplinar e de Psicoloqia

Id on Line Revista Multidisciplinar e de Psicologia

indivíduos optam em ingressar numa carreira profissional no setor público devido a fatores como remuneração razoável e estabilidade, no entanto a motivação no trabalho é alcançada à proporção que é oferecida a satisfação das necessidades de auto-desenvolvimento dos funcionários, visto que o dinheiro pode motivar ações de curto prazo, mas por si só não aumenta o comprometimento e a produtividade das pessoas com uma organização.

Entre as limitações deste artigo, evidencia-se aquelas inerentes a uma nova proposta: A necessidade de testar o GPPC na prática e propor melhorias na PMA.Com relação às sugestões decorrentes desta pesquisa, no tocante a gestão por competências, seria interessante verificar como a aplicação da GPPC poderia ocorrer, bem como a identificação de atributos organizacionais da PMA e as características pessoais (satisfação e motivação) dos servidores que melhorariam na prática da GPPC.

\section{Referências}

AMARAL, Roniberto Morato. Gestão De Pessoas Por Competências Em Organizações Públicas. XV seminário nacional de bibliotecas universitárias. Disponível em <http://www.sbu.unicamp.br/snbu2008/anais/site/pdfs/2594.pdf.> Acesso em 01.Fev.2016.

ANDRADE, C. R.; PEREIRA, L. Z.; CKAGNAZAROFF, I. B. Elementos de satisfação e insatisfação no trabalho operacional:revisitando Herzberg. Revista Gestão \& Tecnologia, v. 7, n. 1, p. 67-89, 2007.

BATISTA, C. S.; SANTOS, J. N. Motivação e Confiabilidade Humana: uma Análise da Percepção do Indivíduo. Revista de Administração FACES Journal, v. 14, n. 4, p. 117-137, 2015.

BERGUE, S. T. Gestão de pessoas em organizações públicas. 3. ed. Caxias doSul, RS: Educs, 2010.

BRASIL. Decreto n. 5707 de 23 de Fevereiro de 2006. Institui a Política e as Diretrizes para o Desenvolvimento de Pessoal da administração pública federal direta, autárquica e fundacional, e regulamenta dispositivos da Lei no 8.112, de 11 de dezembro de 1990. Disponível em< http://www.planalto.gov.br/ccivil_03/_Ato2004-2006/2006/Decreto/D5707.htm>Acesso em 27. Jan.2016

CARVALHO, Antonio.A motivação do servidor público municipal.Disponível em: <http://rr2008.galeon.com/productos1518190.html>. Acesso em:28. Jan.2016

CAPPI, M. N.; ARAUJO, B. F. V. B. Satisfação no Trabalho, Comprometimento Organizacional e Intenção de Sair: um Estudo Entre as Gerações X e Y. REAd. Revista Eletrônica de Administração, v. 21 , n. 3, p. 576-600, 2015.

COMINI, G. M.; KONUMA, C. M.; SANTOS, A. L. D. S. L. D. Sistema de gestão de pessoas por competências: um olhar crítico para a dimensão do desenvolvimento individual. Gestão \& Regionalidade, v. 24, n. 69, art. 113, p. 6-18, 2008.

CORREAA. Kenneth .Modelo de questionário de pesquisa de clima organizacional para pequenas e médias empresas. Disponível em<http://www.administracaoegestao.com.br/pesquisa-de-clima- 
Id on Line Revista Multidisciplinar e de Psicoloqia

Id on Line Revista Multidisciplinar e de Psicologia

organizacional/modelo-de-questionario-de-pesquisa-de-clima-organizacional-para-pequenas-e-mediasempresas/> Acesso em 27. Jan.2016

CRESWELL, J. W. Projeto de pesquisa: métodos qualitativo, quantitativo e misto. 2 ed. Porto Alegre: Artmed, 2007.

DUTRA, J. S. Competências: conceitos e instrumentos para a gestão depessoas na empresa moderna. São Paulo: Atlas, 2004

ELGENNENI, Sara Maria de Melo. Psicologia organizacional. São Paulo: Pearson education do Brasil,2010.

ENAP. Gestão por competências em organizações de governo. Mesa-redondade pesquisa ação Brasília: ENAP, 2005.

KLEIN, Fabio Alvim; MASCARENHAS, Andre Ofenhejm. Motivação no Serviço Público: Efeitos Sobre a Retenção e Satisfação Profissional dos Gestores Governamentais. In: XXXVIII Encontro Nacional dos Programas de Pós-Graduação em Administração, Rio de Janeiro, 2014.

LEME, Rogério. Aplicação Prática de Gestão de Pessoas por Competências: mapeamento, treinamento, seleção, avaliação e mensuração de resultados de treinamentos. Rio de Janeiro: Qualitymark, 2005.

LIMA et al .Anilton José. Um Olhar Sobre A Satisfação No Trabalho: Estudo Em Organização Multinacional Do Setor De Usinagem No Estado De Minas Gerais. Disponível em <http://www.spell.org.br/documentos/ver/38877/um-olhar-sobre-a-satisfacao-no-trabalho--estudo-emorganizacao-multinacional-do-setor-de-usinagem-no-estado-de-minas-gerais> Acesso em 28.Jan.2016

LIRA, M.; SILVA, V. P. G. Motivação Intrínseca vs. Motivação Extrínseca: a Aplicação da Escala WPI no Contexto do Setor Público Português . Revista de Gestão, Finanças e Contabilidade, v. 5, n. 4, p. 171-195, 2015.

MASLOW, A. A Psicologia do Ser. Rio de Janeiro: Eldorado Tijuca, 1996.

MOREIRA, Walter. Revisão de Literatura e Desenvolvimento Científico: conceitos e estratégias para confecção. Disponível em <https://portais.ufg.br/up/19/o/Revis_o_de_Literatura_e_desenvolvimento_cient_fico.pdf.> Acesso em 23. Mar.2016

OLIVEIRA, Arcelí Ângela Anzolin; COSTA; Gisele Maria Tonin Da; ZANIVAN Rafaela Pauletti. Motivação E Comprometimento Do Servidor Público Municipal. RACI, Getúlio Vargas, v.8, n.17, Jan./jun. 2014.

OLIVEIRA, Lucas Reno; KROM, Valdevino. Estabilidade do servidor público: uma análise da produtividade à luz das teorias de motivação. In: IV Encontro Latino Americano de Pós-Graduação Universidade do Vale do Paraíba, São José dos Campos, 2004.

OLIVEIRA, José Arimatésde; MEDEIROS.Maria da Penha Machado.Gestão de Pessoas no Setor Público. Florianópolis : Departamento de Ciências da Administração/ UFSC; [Brasília] : CAPES : $\mathrm{UAB}, 2011$.

MUNCK, L.; MUNCK, M. M.; SOUZA, R. B. Gestão de pessoas por competências: análise de repercussões dez anos pós-implantação. Revista de Administração Mackenzie, v. 12, n. 1, art. 124, p. 4-52, 2011. 
NODARI, C. H.; BÓ, G. D.; CAMARGO, M. E. Turnover e satisfação no trabalho em empresas multinacionais: um estudo de caso. Revista de Administração da Unimep, v. 8, n. 2, p. 1-16, 2010.

PAULA, P.; STEFANO, S. R.; ANDRADE, S. M.; ZAMPIER, M. A. Clima e cultura organizacional em uma organização pública. Gestão \& Regionalidade, v. 27, n. 81, art. 3, p. 59-73, 2011

PATRÍCIO, Z.M.; CASAGRANDE, J.L. (org). Qualidade de vida do trabalhador: uma abordagem qualitativa do ser humano através de novos paradigmas. Florianópolis: PCA, 1999.

RODRIGUES, W. A.; REIS NETO, M. T.; GONÇALVES FILHO, C. As influências na motivação para o trabalho em ambientes com metas e recompensas: um estudo no setor público. Revista de Administração Pública, v. 48, n. 1, p. 253-273, 2014.

RUTKOWSKI, Jacqueline. Qualidade no serviço público: estudo de caso. Gestão \& produção, v.5, n.3, p. 284-297, dez. 1998

TAKAHASHI, A. R. W.; LEMOS, M. R.; SOUZA, C. P. S. Motivação no serviço público e permanência na carreira militar da Polícia Militar do Paraná/Brasil. Desenvolvimento em Questão, v. 13, n. 29, p. 311-354, 2015.

VIEIRA, et al. Motivação na Administração Pública: considerações teóricas sobre a aplicabilidade dos pressupostos das teorias motivacionais na esfera pública. Revista ADMpg Gestão Estratégica, v. 4, n. 1, 2011.

\section{Como citar este artigo (Formato ABNT):}

MACÊDO, D.S.; CASSUNDÉ, F.R.S.A. O desenvolvimento de Competências e o Serviço Público: Um estudo de caso sobre Motivação com Funcionários da Prefeitura de Afrânio - PE. Id on Line Revista Multidisciplinar e de Psicologia, Julho de 2016, vol.10, n.30, Supl 2. p. 229-244. ISSN 1981-1179.

Recebido: 05/05/2016

Aceito: 17/05/2016 